\title{
LA-UR-97- 9051
}

Approved for public release;

- distribution is unlimited.

TITLE: VIBRATIONAL DYNAMICS OF CRYSTALLINE L-ALANINE

CONF-970814--

AUTHOR(S):

Heloisa N. Bordallo, LANSCE-12

Mariette Barthes, GDPC, Universite Montpellier

Juergen Eckert, LANSCE-12

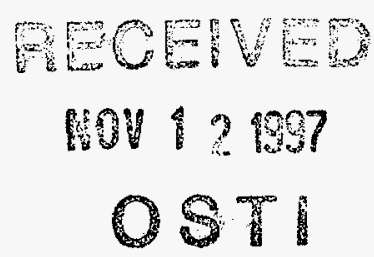

SUBMITTED TO:

International Conference on Neutron Scattering, August 1997, Toronto Canada

Physica B Journal

\section{Los Alamos}

\section{NATIONAL LABORATORY}

Los Alamos National Laboratory, an affirmative action/equal opportunity employer, is operated by the University of California for the U.S. Department of Energy under contract W-7405-ENG-36. By acceptance of this article, the publisher recognizes that the U.S. Government retains a nonexclusive, royalty-free license to publish or reproduce the published form of this contribution, or to allow others to do so, for U.S. Government purposes. The Los Alamos National Laboratory requests that the publisher identify this article as work performed under the auspices of the U.S. Department of Energy. The Los Alamos National Laboratory strongly supports academic freedom and a researcher's right to publish; as an institution, however, the Laboratory does not endorse the viewpoint of a publication or guarantee its technical correctness. 


\section{DISCLAMIER}

Portions of this document may be illegible in electronic image products. Images are produced from the best available original document. 


\section{DISCLAIMER}

This report was prepared as an account of work sponsored by an agency of the United States Government. Neither the United States Government nor any agency thereof, nor any of their employees, makes any warranty, express or implied, or assumes any legal liability or responsibility for the accuracy, completeness, or usefulness of any information, apparatus, product, or process disclosed, or represents that its use would not infringe privately owned rights. Reference herein to any specific commercial product, process, or service by trade name, trademark, manufacturer, or otherwise does not necessarily constitute or imply its endorsement, recommendation, or favoring by the United States Government or any agency thereof. The views and opinions of authors expressed herein do not necessarily state or reflect those of the United States Government or any agency thereof. 


\title{
Vibrational Dynamics of Crystalline L-Alanine
}

\author{
Heloisa. N. Bordallo", Mariette Barthes", and Juergen Eckert" \\ "GDPC, Universite Montpellier II, Montpellier, F-34905, FRANCE \\ "MLNSC, Los Alamos National Laboratory, Los Alamos, NM87545, USA
}

\begin{abstract}
We report here a new, complete vibrational analysis of L-alanine and L-alanine- $\mathrm{d}_{4}$ which utilizes IINS intensities in addition to frequency information. Our study clarifies a number of important issues on the vibrational dynamics of this molecule and presents a selfconsistent force field for the molecular vibrations in crystalline L-alanine.
\end{abstract}

\section{Introduction.}

L-alanine $\left(\mathrm{CH}_{3} \mathrm{CH}\left(\mathrm{NH}_{3}{ }^{+}\right) \mathrm{CO}_{2}{ }^{-}\right)$is one of the simplest amino-acids and may be considered to be the basic building block constituting many polypeptides or alpha-helical proteins. The molecule is relatively flexible which results in significant coupling between some lattice modes and internal molecular vibrations[1]. It has been proposed[2] that localization of vibrational energy occurs in L-alanine as in related solids such as acetanilide or $\mathrm{N}$-methylacetamide [3], where temperature dependent anomalies of the optical spectra have been attributed to localized, nonlinear excitations . 
We initiated the present vibrational spectroscopic investigation of L-alanine and its partially deuterated isotopomer L-alanine- $\mathrm{d}_{4}\left(\mathrm{CD}_{3} \mathrm{CD}\left(\mathrm{NH}_{3}{ }^{+}\right) \mathrm{CO}_{2}^{-}\right)$by incoherent inelastic neutron scattering (IINS) as a preliminary step in our study of the short polypeptide Tryp[Ala $]_{15}$. This has also been found to exhibit anomalies in the amide vibrations, which are thought to result from nonlinear or "polaronic " excitations by coupling the proton motion in the hydrogen-bond to lattice modes [4].

The crystal structure of zwitterionic L-alanine (space group $\mathrm{P} 2_{1} 2_{1} 2_{1}$ ) contains three networks of intermolecular hydrogen bonds linking a positively charged ammonium group to a carboxylate group on a neighboring molecule.The vibrational dynamics of L-alanine have previously been described $[1,5,6]$. Urey-Bradley or valence force fields have been also reported [7-9] as well as group frequency assignments[1,6,10].

We report here new IINS measurements and a vibrational analysis of L-alanine and L-alanine- $d_{4}$ which utilizes IINS intensities in addition to frequency information. The use of both isotopomers resulted in a self-consistent force field for and assignment of the molecular vibrations in L-alanine. Some details of the calculation as well as a comparison of calculated and observed INS spectra are presented below.

\section{Experimental details.}

Polycrystalline samples of L-alanine were obtained from Aldrich, and L-alanine- $\mathrm{d}_{4}$ from Cambride Isotope Laboratory (isotopic purity $>98 \%$ ). The IINS data reported in this work were collected on the FDS spectrometer at the Manuel Lujan Jr. Neutron Scattering

Center of Los Alamos National Laboratory. The FDS spectra were obtained [11] by numerical deconvolution of the instrumental function from the raw data.

\section{Results and Discussion.}

The intermolecular force field was refined by fitting the vibrational frequencies and IINS intensities to force constants derived from a normal-coordinate analysis using the 
program CLIMAX [12] with-structural parameters for the molecule given by Destro et al. [13]. The molecular vibrations can be described by 38 internal coordinates, which are associated with the force constants by means of a constraint matrix. The force constants are defined in terms of locally symmetric groups $\left(\mathrm{CO}_{2}^{-}, \mathrm{NH}_{3}^{+}\right.$, and $\left.\mathrm{CH}_{3}\right)$ and bondstretching and bond angle-bending coordinates for the backbone of the molecule. Initial values of diagonal force constants for the zeroeth-order calculation were obtained from the work of Susi et Byler [8]. Table I lists the force constants for both isotopomers that were required to give a satisfactory fit of both intensities and frequencies. Since the number of interaction force constants employed is relatively small, the force field may not be expected to reproduce all vibrations equally well

Observed IINS spectra at $20 \mathrm{~K}$ for L-alanine and L-alanine- $\mathrm{d}_{4}$ are shown in Figure 1. for the frequency range $50-2000 \mathrm{~cm}^{-1}$. Details of the frequency assignments will be reported in a future publication. We restrict our comments on assignments in the following to some of the more prominent bands in the IINS spectra. In the midfrequency region ( 800 - $1700 \mathrm{~cm}^{-1}$ ) coupling between vibrational modes makes assignments of the modes difficult. However, the introduction of the interaction force constants 24 and 26 made it possibleto assign the rocking vibrations of the $\mathrm{NH}_{3}{ }^{+}$and $\mathrm{CH}_{3}$ groups in the same region in which the C-C-N stretching vibrations are also observed $[5,6]$.

Our results showed an extensive mixing of carboxyl stretching mode with the $v\left(\mathrm{C}_{2}-\mathrm{C}_{1}\right)$ vibration, the methyne $\mathrm{CH}$ bending coordinates and the $\mathrm{NH}_{3}{ }^{+}$modes, and the fit is relatively poor in this region. A controversy exists in the literature concerning this mixing since the carboxyl stretching fundamentals are often thought to be localized modes, selftrapped by interaction with phonons. Nonetheless, a similar behavior is also observed in other substances having a $\mathrm{CO}_{2}$ moiety such as glycine $[14,15]$. Furthermore, as the charges of the $\mathrm{L}$-alanine are localized at the $\mathrm{NH}_{3}{ }^{+}$and $\mathrm{CO}_{2}^{-}$groups, one expects greater polarization 
effects, due to the charge centers interaction, on the $\mathrm{NH}_{3}^{+}-\mathrm{CO}_{2}$ intermolecular modes, and on the modes associated to these groups than on the other internal modes.

The $\mathrm{NH}_{3}$ torsion at $480 \mathrm{~cm}^{-1}$ is the most intense band in the IINS spectrum. The frequency and width of this mode have been shown in the previous literature $[1,16]$ to have a large and unusual temperature dependence which is currently under investigation by us. The $\mathrm{CH}_{3}$ torsion is observed at $265 \mathrm{~cm}^{-1}$ in the IINS and at about 400 and $280 \mathrm{~cm}^{-1}$ in Raman scattering. Machida[5] calculated a rather large factor group splitting (around 100 $\mathrm{cm}-1$ ) for the $\mathrm{CH}_{3}$ modes resulting from the proximity of methyl from neighboring molecules. We do not, however, find any contribution from the methyl torsion in the IINS band $404 \mathrm{~cm}^{-1}$.

The calculated spectra for both isotopomers of L-alanine are compared in Fig. 2. Reference to Fig. 1 shows that the agreement with experiment is satisfactory. This is particularly true in view of the fact that the present type of analysis treats the molecule as isolated. A computational treatment based on the crystalline unit cell with explicit use of intermolecular interactions would, however, be expected to improve this agreement substantially. Moreover, such a calculation is more realistic and would be of great importance in assessing issues [2-4] related to energy transport and localization in these biological model systems.

Acknowledgments. The authors wish to thank G.J.Kearley for his asistance with the use of the program CLIMAX. This work has benefitted from the use of facilities at the Manuel Lujan Jr. Neutron Scattering Center, a National User Facility funded as such by the office of basic Energy Sciences, U.S. Department of Energy. 


\section{References.}

1. C.H. Wang and R.D. Storms, J. Chem. Phys. 55, 3291 (1971)

2. A. Migliori, P. Maxton, A.M. Clogston, E. Zirngiebl and M. Lowe, Phys. Rev. B 38(18), 13464 (1988)

3. M. Barthes, G. de Nunzio and M. Ribet, Synthetic Metals (in press).

4. V.Helenius (personal communication).

5. K. Machida, A. Kagayama, Y. Saito and T. Uno, Spectrochim. Acta 34A(4), 909 (1978)

6. J. Bandekar, L. Genzel, F. Kremer and L. Santo, Spectrochim. Acta 39A(4), 357 (1983)

7. M. Diem, P.L. Polavarapu, M. Oboodi and L.A. Nafie, J. Am. Chem. Soc. 104, 3329 (1982)

8. H. Susi and D.M. Byler, J. Mol. Struct. 63, 1 (1980)

9. K. Fukushima, T. Onishi, T. Shimanouchi and S-I. Mizushima, Spectrochim. Acta 15, 236 (1959)

10. D.M. Byler and H. Susi, Spectrochim. Acta 35A(4), 1365 (1979)

11. D. S. Sivia, P. Vorderwisch and R. N. Silver, Nucl. Instr. and Methods A290, 492 (1990).

12. G.J. Kearley, Nucl. Instrum. Methods Phys. Res. A 354, 53 (1995)

13. R. Destro, R.E. Marsh and R. Bianchi, J. Phys. Chem. 92, 966 (1988)

14. S. Krimm, in "Biological Applications of Raman Spectroscopy", edited by T. Spiro (Wiley, New York, 1987), pg. 1.

15 . F. Fillaux, J.P. Fontaine, M.H. Baron, N. Leygue, G.J. Kearley, J. Tomkinson, Biophysical Chemistry 53, 155 (1994)

16. S. Forss, J. Raman Spectrosc. 12(3), 266 (1982) 
Table 1. Force constants (FC) obtained from fitting frequencies and IINS spectra of Lalanine (1) and L-alanine- $\mathrm{d}_{4}$ (2) using CLIMAX [12]. $\mathrm{C}_{1}$ is the carboxyl group carbon atom, $C_{2}$ the methyne- and $C_{3}$ the methyl group carbon atom.

\begin{tabular}{|c|c|c|c|c|c|c|c|}
\hline$\overline{F C}$ & 1 & 2 & coordinate & $\mathrm{FC}$ & 1 & 2 & coordinate \\
\hline 1 & 5.08 & 5.20 & $\mathrm{v}\left(\mathrm{NH}_{3}^{+}\right)$ & 19 & 4.60 & 4.78 & $v(C-N)$ \\
\hline 2 & 0.51 & 0.53 & $\delta\left(\mathrm{NH}_{3}^{+}\right)$ & 20 & 1.47 & 1.23 & $\delta\left(N-C_{2}-C_{3}\right)$ \\
\hline 3 & 0.92 & 0.76 & $\rho\left(\mathrm{NH}_{3}{ }^{+}\right)$ & 21 & 1.07 & 0.90 & $\delta\left(N-C_{2}-C_{1}\right)$ \\
\hline 4 & 0.005 & 0.005 & $\tau\left(\mathrm{NH}_{3}\right)^{-}$ & 22 & 1.38 & 0.99 & $\delta\left(C_{1}-C_{2}-C_{3}\right)$ \\
\hline 5 & $4 . \overline{7} 1$ & 4.69 & $v\left(\mathrm{CH}_{3}\right)$ & \multicolumn{4}{|c|}{ Interaction force constants } \\
\hline 6 & 0.45 & 0.48 & $\delta\left(\mathrm{CH}_{3}\right)$ & 23 & -0.53 & -0.92 & $\mathrm{v}(\mathrm{C}-\mathrm{N}) / \delta\left(\mathrm{NH}_{3}{ }^{+}\right)$ \\
\hline 7 & 0.88 & 1.23 & $\rho\left(\mathrm{CH}_{3}\right)$ & 24 & 0.005 & 0.06 & $v(\mathrm{C}-\mathrm{N}) / \rho\left(\mathrm{NH}_{3}{ }^{+}\right)$ \\
\hline 8 & 0.001 & 0.001 & $\tau\left(\mathrm{CH}_{3}\right)$ & 25 & 0.081 & 0.14 & $v\left(\mathrm{C}_{2}-\mathrm{C}_{3}\right) / \delta\left(\mathrm{CH}_{3}\right)$ \\
\hline 9 & $4 . \overline{7} 5$ & 4.7 & $v\left(\mathrm{C}_{2}-\mathrm{H}\right)$ & 26 & 0.48 & 0.58 & $v\left(\mathrm{C}_{2}-\mathrm{C}_{3}\right) / \rho\left(\mathrm{CH}_{3}\right)$ \\
\hline 10 & 0.73 & 1.19 & $\delta\left(C_{2}-H\right)$ & 27 & 1.19 & 1.21 & $v\left(\mathrm{C}_{2}-\mathrm{C}_{1}\right) / \delta\left(\mathrm{CO}_{2}\right)$ \\
\hline 11 & 0.23 & 0.001 & $\pi\left(\mathrm{C}_{1}-\mathrm{C}_{2}-\mathrm{H}-\mathrm{C}_{3}\right)$ & 28 & 1.00 & 1.32 & $v\left(\mathrm{C}_{2}-\mathrm{C}_{1}\right) / \rho\left(\mathrm{CO}_{2}\right)$ \\
\hline 12 & 7.1 & 7.2 & $v(C-O)$ & 29 & 0.57 & 0.63 & $v(\mathrm{C}-\mathrm{O}) / \delta\left(\mathrm{CO}_{2}\right)$ \\
\hline 13 & 1.72 & 1.37 & $\delta\left(\mathrm{CO}_{2}\right)$ & 30 & -0.13 & -0.39 & $v(\mathrm{C}-\mathrm{O}) / \mathrm{p}\left(\mathrm{CO}_{2}\right)$ \\
\hline 14 & 1.24 & 1.40 & $\rho\left(\mathrm{CO}_{2}\right)$ & 31 & 1.41 & 0.49 & $v\left(C_{2}-C_{1}\right) / v\left(C_{2}-C_{3}\right)$ \\
\hline 15 & 0.53 & 0.50 & $x\left(\mathrm{CO}_{2}\right)$ & 32 & 1.14 & 1.69 & $v(C-O) / v\left(C_{2}-C_{1}\right)$ \\
\hline 16 & 0.012 & 0.011 & $\tau\left(\mathrm{CO}_{2}\right)$ & 33 & -0.10 & -0.18 & $v(\mathrm{C}-\mathrm{O}) / \delta\left(\mathrm{NH}_{3}{ }^{+}\right)$ \\
\hline 17 & 5.07 & $5 . \overline{3} 1$ & $v\left(C_{2}-C_{3}\right)$ & 34 & 0.08 & 0.05 & $v(\mathrm{C}-\mathrm{O}) / \rho\left(\mathrm{NH}_{3}{ }^{+}\right)$ \\
\hline 18 & 3.69 & 4.53 & $v\left(C_{2}-C_{1}\right)$ & 35 & 0.35 & 0.03 & $v(\mathrm{C}-\mathrm{O}) / \delta\left(\mathrm{C}_{2}-\mathrm{H}\right)$ \\
\hline
\end{tabular}




\section{Figure Cations.}

Fig. 1. Inelastic neutron scattering spectra for $\mathrm{CH}_{3} \mathrm{CH}\left(\mathrm{NH}_{3}{ }^{+}\right) \mathrm{CO}_{2}^{-}$(top) and $\mathrm{CD}_{3} \mathrm{CD}\left(\mathrm{NH}_{3}{ }^{+}\right) \mathrm{CO}_{2}{ }^{-}$(bottom) at $12 \mathrm{~K}$.

Fig. 2. Calculated IINS spectra for L-alanine (top) and L-alanine- $\mathrm{d}_{4}$ (bottom). The bars at the top indicate the positions of the fundamental frequencies, overtones and combination bands. 


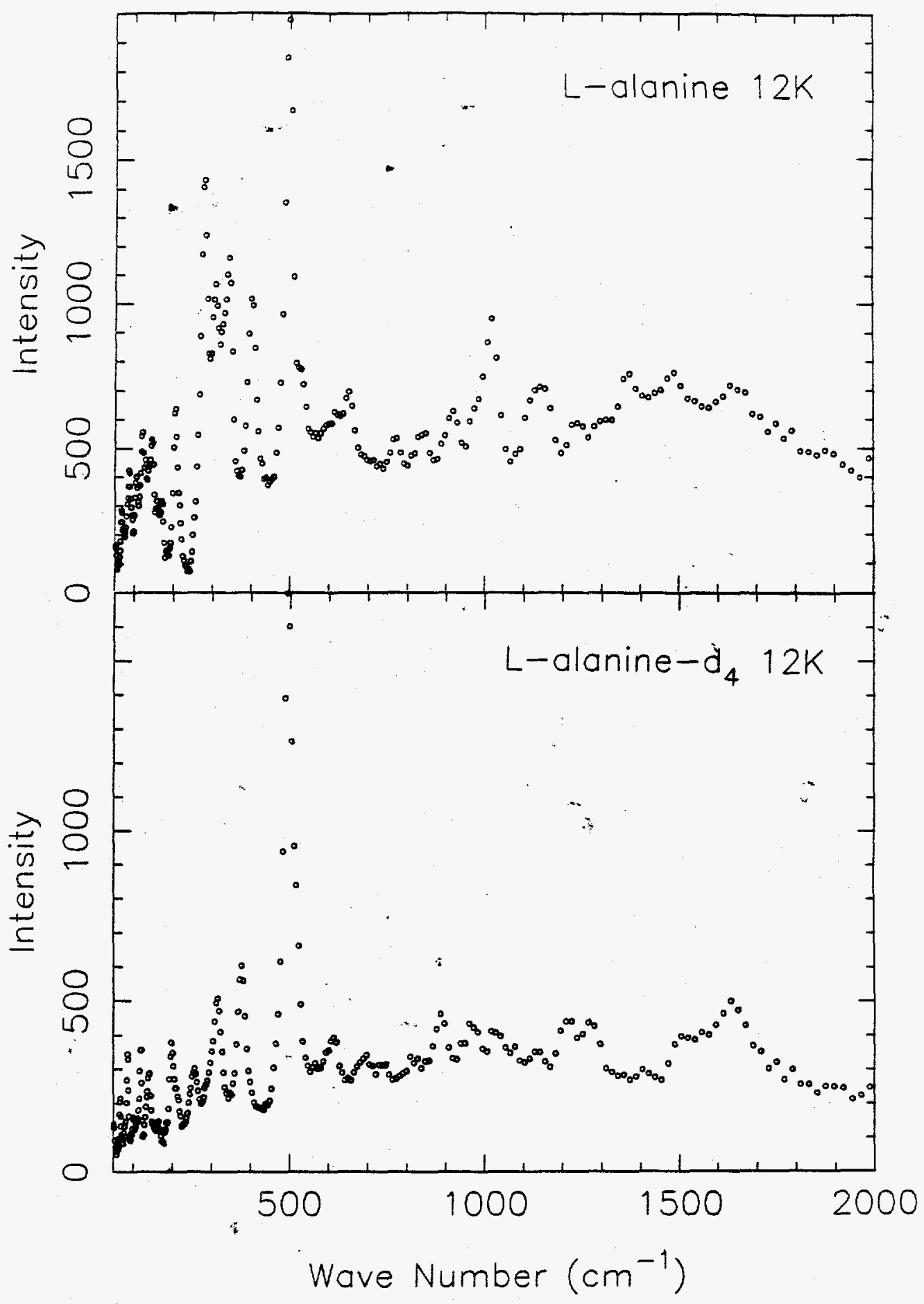




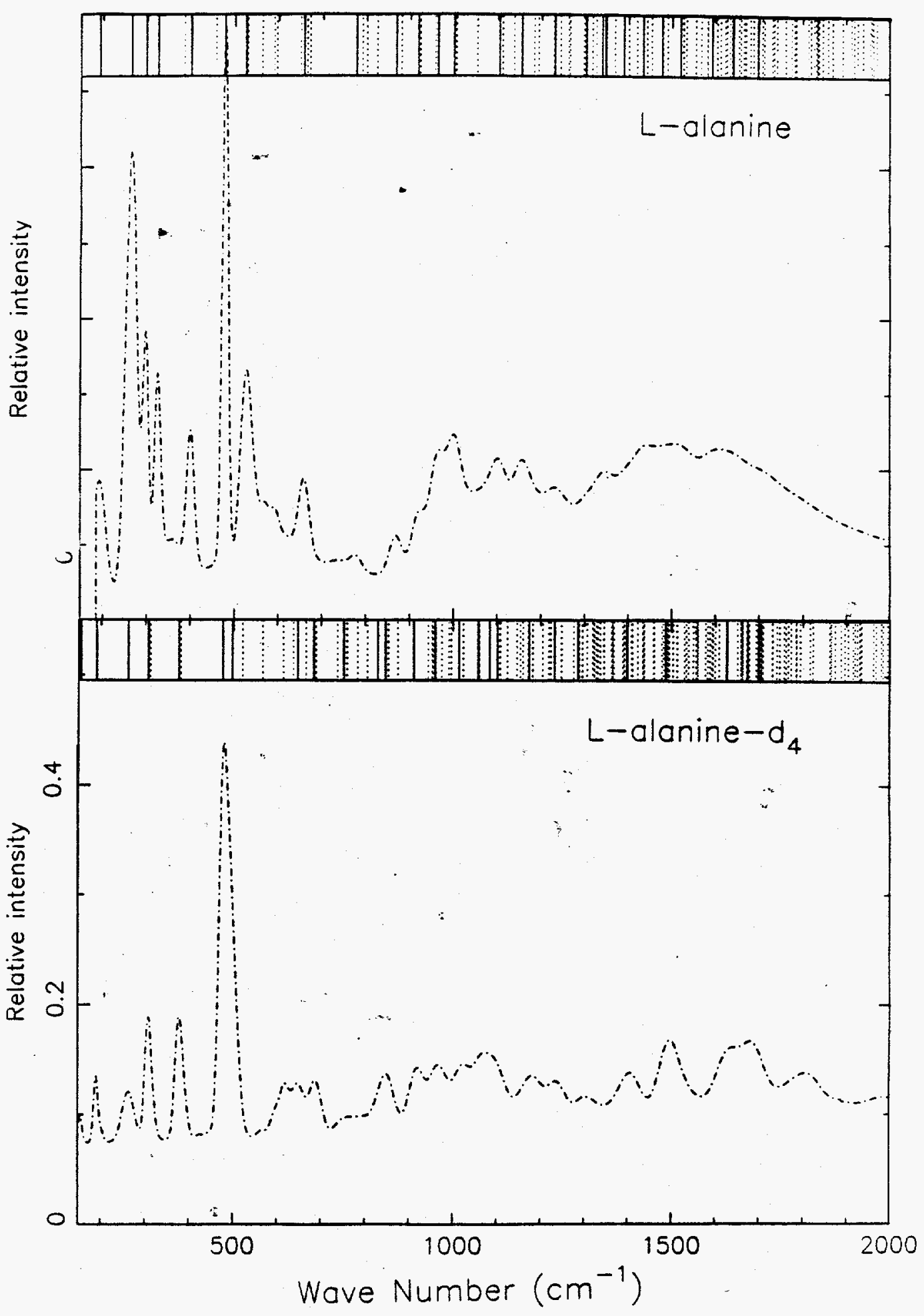

